mov ment just at the point of junction of the fuuiculus with the germinal membrane. At first I thought this was a movement of nutrient fluids from the membrane to the echinococcus; it had very much the appearance, under a low power, of the transmission of fluids as seen in some plants. On further observation with higher powers and careful illumination, I arrived at the conclusion that the motion was caused by the rapid vibratile action of cilia-like processes attached to the hydatid at the point indicated. As the parasites became weak and died, the motion ceased, and I have not had an opportunity of repeating my cbservation. With Beck and Beck's $\frac{1}{0}$ in. objective $I$ obtained a fine view of the movements, but thes were also distinct under the $\frac{-}{s}$ in. and $\frac{1}{5}$ in. glasses.

Iuly, 1870.

\section{REMARKS ON VERSION}

WITH A CASE IN WHICH THE PRESENTING ARM TAS WRENCHED OFF IN THE ENDEAVOUR TO DELIVER.

By AI.EX. MILNE, M.D., L.R.C.P.\&S. ED.

Ir is not very easy to say to whom, amongst obstetricians, the highest pæan ought to be awarded-whether to Paré who taught the value of version; to Chamberlen, who gave us the forceps; to Desgranges, who rescued ergot from the women; or to Simpson, who introduced chloroform. For my own part, I rate Paré's work very highly, because I have found turning of incalculable value in the course of my practice, the most encouraging results being achieved by it. The forceps is, doubtless, one of the most invaluable instruments that was ever invented in connexion with our art; but, apart from its greater risks, as compared with version-that is, in high operations, - the unchallengeable fact remains that the hand, soft as the woman's parts themselves, will often succeed when the instrument utterly fails, and where the only other alternative is the sad one of craniotomy, which is of course, as regards the child, convertible with death. Of more than fifty cases of version in which I have been called to operate, in my own practice and in that of my brethren, six of them were of this nature - that is to say, the forceps were tried by dertrous hands, unsuccessfully, before the turning, which was successful, was resorted to. One of these cases, in which neither Professor Simpson nor myself could get the forceps applied, but in which I succeeded in turning, I reported in the Adinburgh Medical Journal for March, 1867.

Although version is the common proceeding in transverse presentations, in most cases of placenta previa, in convulsions, flooding, \&c., I believe it is not very generally resorted to in contraction of the pelvic brim. I may state that I am one of those who believe that it might be oftener adopted in such cases-that the bi-parietal diameter should be replaced by the narrower bi-mastoid,-in preference to the more critical bigh forceps operation. I have much confidence in version in such instances-a confidence inspired by almost unvarying success. In reporting one of the more recent cases of difficult version which have come in my way, perhaps I may be allowed to state one or two points which axe, in my opinion, conducive to success in this operation.

Turning, I need hardly observe, is, in ordinary instances, as simple as the application of the short forceps; but where the liquor amnii has been long drained away, and the parts have become tumefied and dry; where the uterus is in a state of extreme tonic spasm, and grasps the foetus as in a vice, the case bas deepened in to one of considerable difficulty and danger. The operation may then even have become utterly impracticable, impelling to the unhappy alternative of perforation. The first thing to be done in such a case is, of course, to overcome the spasm. This should be most thoroughly done, otherwise we may be effectually baffled. For this purpose resort was wont to be had to bleeding, to tobacco, or to opium; now we have the more efficient drug, chloroform. This I ply the patient with, on to most complete anxsthesia ( $I$ mean in such diffeult cases), and thus, as a rul: the tetanic uterus relaxes, and entrance is permitted.
I have seen one or two singular cases, where the chloroform failed to overcome the spasm; but these do not happen often. In such circumstances much belp was obtained from tartarated antimony.* I repeat, to succeed, not to be baffled in these extreme instances, orercome the spasm in the most complete manner possible.

As regards the method of operating. I place the patient in the ordinary British left lateral position, with the nate brought a little beyond the edge of tho bed, the knees well drawn towards the abdomen, the right one being well ele rated. There is much difference among obstetric authors in reference to the most suitable band to employ. Dr Robert Lee, a most experienced author, recommends the right; the late Dr. Ramsbotham strongly urged the left Sir James Simpson rather preferred the right; and Dr. Tyler Smith and Churchill also favour the use of this hand. As regards myself, I strongly recommend the left hand and I may observe that I was in the habit of employing it before I noticed (which I did with much satisfaction) Dr. Ramsbotham's cogent reasons for preferring it to the right The left has the following advantages:-1. It is usually rather smaller than the right (in my own case it is markedly so). The value of this is obvious. 2. The canal to be tra rersed is backwards, upwards, and somewhat forwards, and the left hand (and forearm) adapts itself to that curve much more easily than that of the right; that is, with the woman lying in the ordinary obstetric position. You cannot adapt the right hand and arm so well without bending the wrist backwards in an unnatural and uneasy degree. 3. The knuckles of the right hand hitch against the pubes, whereas in the case of the left they are received into the cavity of the sacrum. Tastly. In employing the left hand, the right is free to render important aid externally, either in the way of helping up the head or bearing down the breech. The influence of external mavipulation is often very great. Dr. Braxton Hicks's metbod-the combined external and internal plan-has superior advantages in some cases, such as in placenta prævia and convulsions, and I have reportedt a few such where its value was undoubted but where the uterus is in the tensely spasmodic state, and invests the contained body almost as closely as the egg is covered by its shell, it is utterly impracticable. But I have another plan of my own which I frequently adopt, and which might be termed the combined internal metbod. It is this: with three or four fingers you grasp a foot, or the knee, and make traction downwards, while simultaneously, with the index-finger and thumb of the same hand, you push the presenting part, whether shoulder or head, upwards. A more speedy revolution of the foetus is thus of ten accomplished.

I now subjoin a brief report of the case referred to at the head of this paper.

On the 20th May last Dr. Groves of Trinity requested me to see a woman in labour there, who had fallen under his care on being abandoned by another practitioner after an ineffectual attempt at delivery. It was a case of twins, and the first child, presenting naturally, was delivered without trouble. The second was an arm presentation (dorsoanterior); and the person in attendance, after employing a great deal of force, wrenched the presenting arm completely away. Whether he made any attempt to turn or not previous to the exertion of so much misapplied force is not known, for he remained out of the way after his disastrous failure. Dr. Groves was called after this, and arrived about four hours after the arm was severed. He found the parts so terribly swollen and bruised, and the uterus in such a state of spasm, and encircling the footus so firmly and closely, that it was impossible to reach a foot. On my arrival, about twelve hours after the tearing away of the arm, I found the state of matters to be as follows:-Patient pale and exhausted; pulse rapid and feeble. On making a vaginal examination, I found the parts swollen and lacerated, hot, and besmeared with a dark discharge; the glenoid cavity, with a few ragged shreds of muscle surrounding it, presenting a little below the brim. Dr. Groves placed the patient deeply under the influence of chloroform, and I began inserting my left hand with the view of arriving at a foot. This was a laborious task, the hand having so little room to act, and being so firmly compressed between the

* I hare ref-rred to this potent anfispasmodic power of antimony, where chloroform failed, in my Manual of Materia Medica. c Edinburgh Medical Journal, Nor. 1869. 
uterus and the child. I had two or three times to stop my cautious efforts, in order to rest the arm ; and more than once thought that I should have had to desist from the attempt to turn. In the course of twenty minutes or so, however, I was able to seize hold of a foot, and very shortly afterwards delivery was effected. The child, I need scarcely add, was dead. The woman succumbed after a few days, from sloughing of the vagina and exhaustion, undoubtedly due to the rough treatment she had experienced before the arrival of either Dr. Groves or myself. It is the first maternal death I have had after the operation of turning, and I think I may warrantably flatter myself that in this case the version was not the cause of it.

Edinburgh, Sept. 1870.

\section{REPORT OF}

\section{TWO OPERATIONS PERFORMED UNDER THE INFLUENCE OF NITROUS OXIDE GAS.}

Bx W. HASLAM DAVIS, M.R.C.S.

THe inconvenience arising from the long time needed to produce anæsthesia by chloroform, and the sickness following its use, cause surgeons frequently to perform brief yet painful operations without it. For these reasons I have usually operated for fistula, and amputated fingers, without chloroform. But, having a nervous patient who required the operation for fistula in ano, and could not "screw his courage to the sticking point," I determined to try the effect of nitrous oxide gas. Mr. Crapper, a dentist of this town, who makes, and uses extensively, the gas, gave me several opportunities of seeing it used; and by these I was convinced of the practicability of producing by it insensibility to pain, for a short time, with safety. Mr. Crapper kindly administered the gas, and in two minutes from the application of the inhaler the patient awoke, unconscious that he had been cut, and with his wound dressed.

Shortly after this, I found it needful to amputate a middle finger for necrosis of several months' standing, and again obtained the assistance of Mr. Crapper. In this instance, one inhalation sufficed for the removal of the finger and the head of the metacarpal bone, which proved to be diseased; and after a short interval, during which the hæmorrhage was controlled by the use of cold water, the gas was again given while the wound was stitched up. On recovering his consciousness, the patient said he felt quite well, but wished his finger were off. He had not felt the operation at all. I must state that there was a good deal of muscular spasm, so much as to render it necessary to have the hand firmly held.

In each case there was an absence of sickness after the administration, and the digestion was not disordered.

I think that for the minor operations, and those which can with certainty be done quickly, nitrous oxide gas is much to be preferred to chloroform; but in operations like herniotomy, where it is most desirable to have muscular relaxation and perfect stillness, I should continue to use chloroforn.

Hanley, Staffordshire, July, 1870.

Obuective Tinnitus Aurium.-Dr. Politzer brought before the Medical Society of Vienna on June 10th, 1870, a young girl from whose left ear a rhythmical ticking can be heard. This is perceived even when the girl is asleep, and had been lasting for the last five months. This sound must not be confounded with the ordinary subjective tinnitus aurium, nor with the noise which some people can emit by contraction of the tensor tympani. The patient cannot stop the ticking, nor produce it when a pause has taken place. The sound, however, is no longer heard when the girl pronounces the German vowels $a$ or $e$, nor when the velum is pressed upwards. Dr. Politzer believes that the ticking is caused by the tensor palati mollis pulling from the Eustachian tube to the velum, by drawing the mucous portion of the tube from the cartilaginous part. Dr. Gruber doubted this explanation, and would refer the ticking to the action of the tensor tympani.

\section{gy aftitror}

OF THE PRACTICE OF

\section{MEDICINE AND SURGERY IN THE}

\section{HOSPITALS OF LONDON.}

Nulla autem est alia pro certo noscendi via, nisi quamplurimas et morborum et dissectionum historias, tum aliorum, tum proprias collectas habere, et inter se comparare.-Norgag 1 De Sed. et Caus. Morb., lib. iv. Procmium,

\section{ST. MARY'S HOSPITAL.}

NOTES OF A CLINICAL LECTURE ON CASES OF LUNG INFLAMMATION TREATED BY OPIUM.

By Dr. HANDField Jones.

E. W-, aged twenty-five, a servant, was admitted on the 5th January last, having been ill for two days. She complained of great pain in the left side and some cough. The pain was aggravated by inspiration, and there was hardly any movement of the ribs on that side. There was dulness at the lower part of the left back, and good breathing in the upper part and in all the right back. The tongue was furred and brown; the pulse 120, small, and weak; the temperature 104. Her first symptom had been cough and heaviness; the day following she had felt very cold, and on admission her head was very giddy when she sat up. She was ordered four leeches to the left side and a poultice, and two grains of iodide of potassium in an ounce of citrate of potash mixture, and a grain of opium, three times a day. 'Two days later, the lower half of the left back was very dull, and presented on auscultation marked bronchial breathing, with bronchial voice and weak crepitation; the pulse was 96 ; the expectoration very scanty, of marked yellow colour; the skin warm, the tongue dryish near the tip, and the temperature $104: 36^{\circ}$. On the fourth day the pulse was 100 and good, the temperature $97 \cdot 16^{\circ}$, and the tongue mor $\theta$ moist. On the fifth day the pulse was 88 , the temperature $99 \cdot 7^{\circ}$ and the expectoration mucous and scanty; at the left lower back, bronchial breathing alone was heard during quiet respiration, but crepitation as well on deep inspiration ; tongue moist and clean; there was still some pain in the left side on taking a deep breath. Her medicine was changed to fifteen drops of the solution of perchloride of iron in an ounce of the hospital quinine mixture; and on the seventh day after admission the pulse was 96 , the temperature $98.6^{\circ}$, good breathing was heard at the left base and back, and convalescence was well established.

This was a well-marked case of pleuro-pneumonia, though not a severe one. It came early under treatment-namely, on the third day of the illness,--and defervescence was fully established on the fifth day. It is too much to affirm that the brevity of the attack was the result of the treatment, especially as the fall in temperature was so sudden, more than $7^{\circ} \mathrm{Fahr}$. in four-and-twenty hours. Nevertheless, as the opium, at any rate, was no placebo, as it evidently did not retard recovery, and as it is known to be useful in other inflammations, we shall probably not be far from the truth if we believe that it promoted the cessation of the morbid process.

Another case was that of $\mathrm{G} . \mathrm{H}-$ - aged twenty-seven, a porter. He was admitted on the 16 th of April. He had been recently laid up with rheumatic fever for six weeks. Three days before admission he was taken with pains at the front of the chest; and the day before he had vomited, according to his account, a good deal of blood. He had often had pain after eating, and had been much troubled with flatulence. No enlargement of the liver or spleen was found; the epigastrium mas tender; the tongue moist and rather coated; the bowels were open; the urine was red and rather thick; the pulse 108 and weak; the face pale. He said he felt very weak, and had had the day before very severe pain at the lower left side, about the seventh and eighth costal cartilages. The pain was then especially precordial, and increased by inspiration. The left front was resonant, and breathing was heard down to the third 